\title{
CARCINOMA MICRO-INVASIVO DEL CUELLO UTERINO
}

\author{
Prof. Rubén Darío Guzmán A.* \\ Prof. Alvaro Fonnegra M.** \\ Dr. Jaime Cantillo G.***
}

Existe o nó el carcinoma micro-invasivo del cuello uterino? No se ha dilucidado de una manera exacta la existencia o nó de éste carcinoma. Algunos Patólogos y Ginecólogos consideran que desde el momento que exista ruptura de la membrana basal y una invasión aunque sea mínima del estroma, ya no debe considerarse el carcinoma como micro-invasivo sino netamente invasor; sin embargo la experiencia de algunos autores quienes han tratado éstos casos con cirugía conservadora, como la histerectomía abdominal total, y los han vigilado durante varios años sí aceptan su existencia y consideran que a pesar de que exista una invasión mínima no justifica una cirugía mayor, como es la histerectomía radical, con los graves riesgos que ésta conlleva, sino una cirugía menor, como es la histerectomía abdominal ampliada. Parece que el primero que la describió fue Stoddar y cols. (1) y posteriormente Fennel (2), Reagan y Wentz (3), lo Ilaman Invasión temprana del estroma o microinvasión; no aconsejan llamar microinvasor, pues en esta etapa de carcinogénesis no puede predecirse con exactitud el destino último del epitelio infiltrante. Pueden observarse focos unicéntricos de infiltración, menos a menudo multicéntricos, aunque el número de fo- cos infiltrantes guarda relación, en parte, con el método de estudio. Según estos mismos autores, el epitelio de origen suele ser morfológicamente anormal y si bien en la mayor parte de los casos el epitelio alterado tiene los caracteres que se atribuyen generalmente al carcinoma in situ, a veces los cambios son más característicos de displasia. El estroma se encuentra infiltrado por algunos grupos pequeños de células discretas y circunscritas o por prolongaciones digitiformes, irregulares, pueden observarse también formaciones de queratina, además de la llamada queratinización de células aisladas.

Fennel (2), Hertig (4) y Hamperl (5) han denominado este tipo de invasión "Invasión precoz del estroma". Fluhmann (6), está de acuerdo con los autores arriba citados. Kaufman (7) también cree en la existencia del Ca. microinvasivo. Existen definiciones nada científicas pero significativas; así, algunos autores consideran Ca. microinvasivo, cuando la invasión no pasa del tamaño de una

* Profesor Asociado, Depto. de Obstetricia y Ginecología, Facultad de Medicina (U.N.).

** Profesor Asociado, Depto. de Obstetricia y Ginecología, Facultad de Medicina (U.N.).

*** Instructor Asociado, Depto. de Patología, Facultad de Medicina (U.N.). 
lenteja o de un grano de arroz y otros cuando en un campo microscópico mirado con pequeño aumento se ve invasión del estroma. Autores como Taylor, no lo aceptan.

Parece que lo más aceptado es que para admitir la existencia de este carcinoma se requieren tres requisitos:

1. Que la lesión no traspase la membrana basal más allá de $5 \mathrm{~mm}$.

2. Ausencia de invasión de los espacios linfáticos por trombos malignos.

3. Que no exista confluencia de los diversos focos invasivos, aunque la invasión sea multifocal.

Una cosa importante es el procedimiento para hacer el diagnóstico. La manera más aceptable son las biopsias múltiples adecuadas en los diferentes cuadrantes que incluyan la unión escamo-cilíndrica y aun mejor es la CONIZACION.

En cuanto al tratamiento se ha discutido mucho sobre él; así Fluhmann (6) sostiene que la presencia de una invasión precoz del estroma sospechosa o dudosa no parece contraindicar el tratamiento por medio de la histerectomía total; no obstante, si existe una invasión más extensa ya no será microinvasor sino invasivo y su tratamiento se hará de acuerdo con los conceptos clásicos, o sea histerectomía radical, radioterapia externa o cobaltoterapia.

\section{Material y Métodos}

Presentamos cuatro (4) casos de Ca. microinvasor diagnosticados y tratados en los servicios de Ginecología del Hospital San Juan de Dios de Bogotá y del Instituto Materno Infantil "Concepción Villaveces de Acosta".

\section{Gravidez:}

Multíparas: $\quad 4 \quad 100 \%$

Vemos que todas correspondieron a pacientes multíparas, lo cual está de acuerdo con lo encontrado por todos los autores.

\section{Edad:}

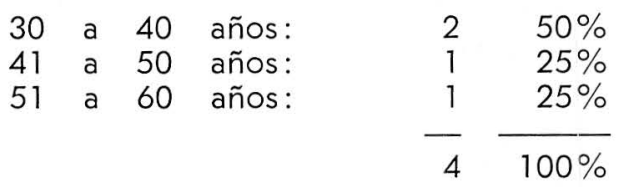

La mayor incidencia ocurrió en las pacientes entre los 30 a los 40 años.

\section{Motivo de consulta:}

Flujo vaginal:

Sens, Cuerpo Ext.:

Hemorragia genital:

$$
\begin{aligned}
& 2 \quad 50 \% \\
& 1 \quad 25 \% \\
& 1 \quad 25 \% \\
& \text { - } \longdiv { 1 0 0 \% }
\end{aligned}
$$

El mayor motivo de consulta fue flujo vaginal.

\section{Citología vaginal:}

$\begin{array}{lrr}\text { A5 } & 1 & 25 \% \\ \text { A4 } & 2 & 50 \% \\ \text { No Cit. } & 1 & 25 \% \\ & -4 & 100 \%\end{array}$

En todos los casos en que se hizo la citología vaginal fueron positivos.

\section{Estade, del cuello uterino:}

Erosión

$4 \quad 100 \%$

En todos los casos existía lesión cervical, tipo erosión. 
Biopsia del cuello uterino:

Ca. In situ con inv. glandular

Cerv. Cren. metaplasia escamosa

Ca. in situ

Ca. microinvasivo

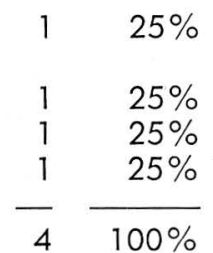

Como vemos en el cuadro anterior en un sólo caso el diagnóstico de microinvasivo se encontró en la biopsia cervical.

\section{Conización :}

Ca in situ

Técnicamente imposible

Ca. microinvasivo

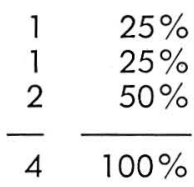

En 2 casos se encontró en el cono ca. microinvasivo y en otro ca. in situ; en el segundo caso no se pudo efectuar la conización por ser técnicamente imposible, ya que las condiciones del cuello uterino no lo permitían.

\section{Tumor residual:}

En ningún caso se encontró tumor residual en la línea de resección.

\section{Complicaciones de la conización:}

Ningún caso hubo complicación durante el acto quirúrgico ni después del mismo.

\section{Tratamiento final:}

Histerectomía abdominal ampliada

Histerectomía abdominal SOB

Histerectomía radical
Es criticable que a una paciente se le sometió a una Histerectomía Radical, la cual presentó como complicación en el acto quirúrgico ruptura de vejiga y sigmoide. Una urografía posterior mostró hidronefrosis derecha; se le practicó nefrectomía por abscesos múltiples. Consideramos que la conducta fue muy extensa e inadecuada. Otros dos casos se les sometió, además de la histerectomía, salpingooforectomía bilateral sin existir patología anexial asociada.

Creemos que la mejor conducta es la histerectomía abdominal ampliada sin extirpación de anexos.

\section{Anatomía patológica del útero:}

En los 3 primeros casos se encontró en el cérvix ca. microinvasivo; en el último no se encontró la invasión lo que presupone que el ca. microinvasor se extirpó en la conización.

\section{Controles:}

1 a 2 meses

2 a 5 meses

31 meses

Sin control

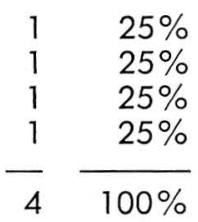

El mayor control fue el de una paciente de 31 meses; otro es muy reciente pues apenas tiene de intervenida tres meses, otro volvió hasta los 5 meses y el último caso desde que se intervino no volvió más a control.

\section{Resumen y Comentarios}

1. Se presentan los conceptos de los diferentes autores sobre la existencia o nó del ca. microinvasor y las diferentes definiciones sobre tal afección.

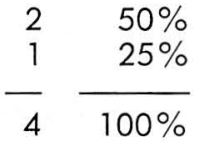

2. Se presentan cuatro (4) casos diagnosticados y tratados en nuestro servicio. 
3. Esta afección ocurrió en mujeres multíparas, con mayor incidencia entre los 30 y 40 años.

4. El motivo principal de consulta fue flujo genital, las citologías fueron positivas; en todas existía lesión cervical, tipo erosión.

5. En un solo caso se halló ca. microinvasor en la conización. En ningún caso se encontró tumor residual en la línea de resección. A la biopsia, sólo se encontró ca. microinvasivo en un caso.

6. El tratamiento final fue histerectomía abdominal sola o con SOB. Criticamos la extirpación de los anexos $\sin$ existir patología anexial asociada.

En un caso se practicó histerectomía radical, cirugía extensa y con alto riesgo; esta enferma presentó como complicación durante el acto quirúrgico ruptura de vejiga y sigmoide y posteriormente, hubo que practicarle nefrectomía por abscesos múltiples del riñón.

7. Consideramos que la conducta más adecuada es la histerectomía abdominal ampliada, sin extirpación de los anexos, es decir, se asimila a un Ca. In situ del cuello uterino.

\section{Resumen y Comentarios}

1. Se presentan los conceptos de los diferentes autores sobre la existencia o nó del $\mathrm{Ca}$. microinvasor $\mathrm{y}$ las diferentes definiciones sobre tal afección.

7. Consideramos que la conducta más adecuada es la histerectomía abdominal ampliada, sin extirpación de los anexos, es decir, se asimila a un Ca. In Situ del cuello uterino.

\section{Summary and Comments}

1. The concept of the different authors on the existence or absence of micro-invasor ca. and the different definitions on such illness is given.

7. We believe that the most appropriate action is enlarged abdominal hysterectomy, without extirpation of annexes, that is, assimilated to a ca. in situ in the cervix uteri.

\section{BIBLIOGRAFIA}

1 STODDARD, L. B.: En McManus Progress in Fundamental Medicine. Filadelfia, Lea \&

Febiger, 1952.

2 FENNELL, R. H. Jr.: Cancer, 8, 302, 1955.

3 REAGAN W. JAMES. WENTZ W. BUDD: Génesis del carcinoma del cuello uterino. Clínicas Obstétricas y Ginecológicas. Diciembre de 1967.

4 HERTIG A. T. y YOUNGE P. A.: Am. J. Obst. \& Gynec. 64, 807. 1952.

5 HAMPERL $H$. KAUFMAN P., OBERT, K. G., Y SCHNEPPENHEIM, P.: Virchow's Arch. Path. Anat., 331, 51, 1958.

6 FLUHMANN C. FREDERIC: El cuello uterino y sus enfermedades. Salvat Editores, Primera Edición. 1963.

7 KAUFMAN RAYMOND $\mathrm{H}$.: Valoración por cotes en congelación de las piezas de conización cervical. Clínicas Obstétricas y Ginecológicas. Diciembre de 1967. 